\title{
UN TAPIZ FENICIO EN GALERA (GRANADA, ESPAÑA). TAPICES Y TEJIDOS HISPANO-FENICIOS
}

\author{
A PHOENICIAN TAPESTRY IN GALERA (GRANADA, SPAIN). \\ HISPANO-PHOENICIAN TAPESTRIES AND FABRICS
}

MARTÍN ALMAGRO-GORBEA
Real Academia de la Historia

Los tejidos fenicios gozaron de justa fama en la Antigüedad, de la que se hace eco la Biblia $(E z .27)^{1}$ y los escritores clásicos desde la Iliada (VI, 289-294). A pesar de ello, es el campo del rico artesanado feniciopúnico al que menos atención se ha prestado en estos años en que tanto se ha desarrollado la arqueología fenicia. Esta situación se explica en gran medida por la escasez de hallazgos arqueológicos que atraigan a los investigadores y permitan precisar las interesantes informaciones que ofrecen las fuentes escritas. Este motivo nos ha movido a ofrecer el estudio de un tapiz fenicio hallado hace ya casi 100 años, pero que ha pasado prácticamente desapercibido para los estudiosos a pesar de su interés para este campo de estudios.

Se trata de un tapiz usado a modo de alfombra que apareció pintado en el suelo en la tumba 2 de la zona I de la necrópolis ibérica de Tutugi, en la actual Galera, Granada, que, probablemente, es la más extensa y monumental de las necrópolis ibéricas conocidas (Cabré y Motos, 1920; Pereira et alii, 2004). Esta sepultura ocupaba el extremo de dicha zona I, situada en una colina con forma de espolón que queda frente a la ciudad, al otro lado y al Norte del río de Orce y de su zona de huerta y al Sur del barranco de Almacil, entre el camino a la Puebla que se dirige hacia el Nordeste y el camino de Orce, hacia el Este (Fig. 1). J. Cabré y F. de Motos (1920, 19), al publicar la necrópolis, ya consideraron que la zona I debió ser la preferente por las familias y personajes más pudientes de Tútugi, quizás por dar frente a la ciudad $\mathrm{y}$, en todo caso, también cabe suponer que probablemente fuera la zona inicial

1. Ezequiel 27: ...de lino recamado de Egipto eran tus velas para servir de enseña; de azul y púrpura de las islas de Elisa eran tus toldos... (7). Edom ... te pagaba con ... púrpura, recamados, fino lino... (16). Damasco ... te pagaba con ... lana de Suhru... (18). Dedan era tu mercado en telas preciosas para carruajes... (20). Harán, Kanneh, Edén, Sheba, Asur y Kulmer comercian contigo ... toda clase de mercancias: vestidos preciosos, mantos recamados, tapices tejidos en varios colores, fuertes y retorcidas cuerdas... (24) (Lepiski, 1985). de la necrópolis, por ser la más destacada y próxima al núcleo urbano.

La Sepultura 2 de la zona I apareció en una era propiedad de Juan Heras, casi en el centro y ligeramente desviada hacia el Norte (Cabré y Motos, 1920, 21), quien la descubrió al desmontar, hacia inicios del siglo $\mathrm{XX}$, unos cerrillos de forma tumular. Como su descubridor no la llegó a excavar, Cabré y Motos pensaron que aún permanecía intacta y lograron la autorización del dueño del terreno para su estudio, pero los campesinos ya la habían profanado, pues quedaba a unos 30 $\mathrm{cm}$ de la superficie. Esta circunstancia hizo que sólo hallaran algunos fragmentos cerámicos, entre ellos, al parecer, algunos de cerámica ática, ya que aparece en el plano con el punto negro que caracteriza las tumbas con este tipo de ajuar (Cabré y Motos, 1920, lám. IX).

La sepultura era una cámara de forma rectangular, de 2,20 $\mathrm{m}$ de largo por 1,37 $\mathrm{m}$ de ancho, excavada en el terreno de margas yesíferas y orientada de Este a Oeste. Sin embargo, ofreció el interés de que sus paredes estaban decoradas con pinturas murales, lo mismo que el pavimento. Sus excavadores indican cómo, tras

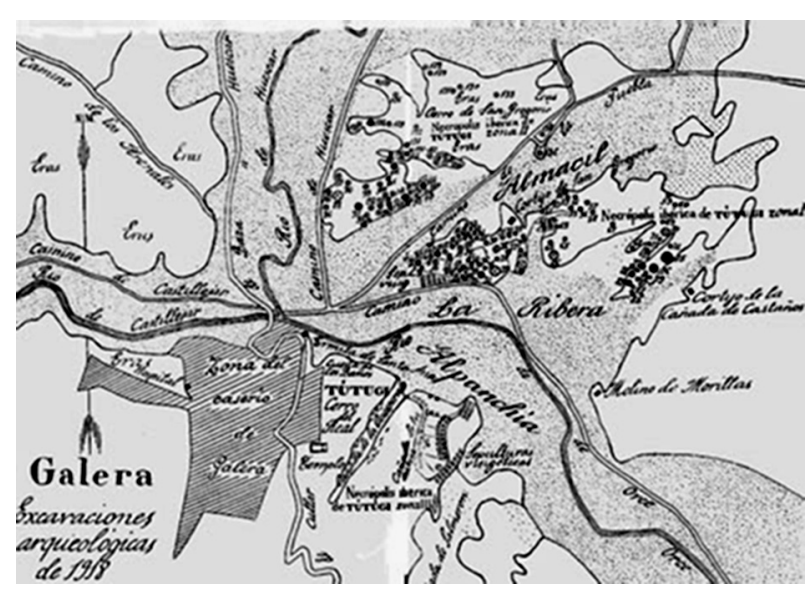

Figura 1: Mapa de la necrópolis de Galera. En el centro, la tumba 2 del área I, atribuible a un rey ibérico de Tutugi (Según J. Cabré y F. de Motos). 
la excavación de la cámara, se revocó el piso y las paredes con yeso y luego fue pintado todo él. F. Cabré y F. de Motos (1920, 21, lám. IX) sólo reprodujeron en una lámina las pinturas del suelo, que son las aquí analizadas, pero ofrecieron también una breve descripción que parece oportuno recoger textualmente, ya que en la actualidad todas las pinturas han desaparecido. «Estas pinturas no serían las hechas cuando se construyó esta sepultura, sino que pertenecen a una segunda época o a su restauración, porque se ve muy bien que al descascarillarse parte de ellas, debajo aparecen nuevos motivos ornamentales, con colores opuestos a los de encima, y además subsisten todavía manchas rojizas debidas a la oxidación de los hierros del ajuar primitivo, manchas que han traspasado de abajo a arriba la capa de pinturas más moderna. Por tanto, los motivos decorativos de la primera época fueron todos enjalbegados con una capa recia, y sobre ella desarrollóse la segunda composición. En ella interviene, ocupando todo el pavimento, un gran rectángulo de color rojo, en el que se dejaron veinticuatro espacios para figurar en ellos especies de aras (en realidad, son flores de loto que, por error, se interpretan invertidas), sobre las que aparecen medias lunas. Las aras se destacan, alternando por series, ya sobre fondo negro, ya sobre el blanco del enjalbegado; en las que tienen su fondo obscuro, la media luna es blanca, y al contrario en las series opuestas. Otro tanto acontece, con el mo-

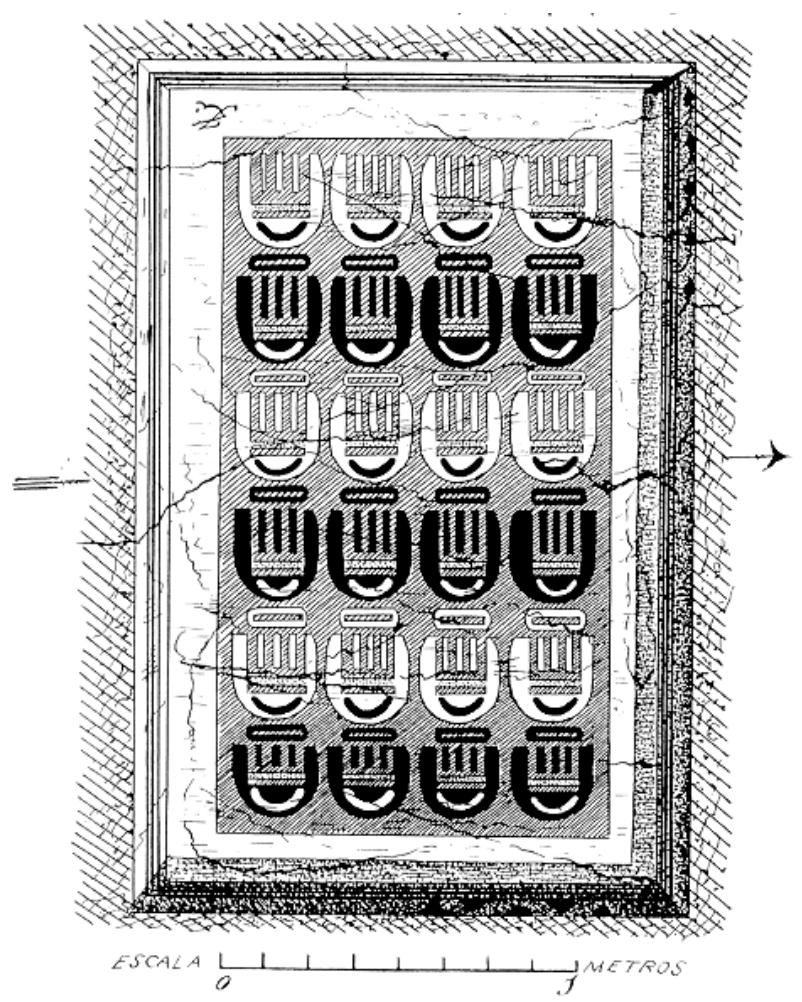

Figura 2: Tapiz utilizado como alfombra pintado en el suelo de la tumba 2 del área I de la necrópolis de Galera (Según J. Cabré). tivo inferior de las aras, y sobre éstas y debajo de las lunas se divisa una línea de color amarillo.

En las paredes variaba la decoración, pues aún se conservaba un zócalo, de ocho centímetros de anchura con tres trazos paralelos; y a partir de ese zócalo se pintaron extrañas combinaciones geométricas y florales, que debieron recubrir toda la superficie de los muros. Innumerables fragmentos de estuco, decorados siempre en rojo, yacían unos recubriendo el pavimento y otros, sin desprenderse, ocupando su lugar propio. En estos últimos se veían con preferencia fajas de hojas de hiedra y de zigs-zágs o dientes de sierra».

En 1954, esta pintura de Galera fue de nuevo publicada por A. García Bellido (1954, 600-601, fig. 532) al tratar de la pintura mayor entre los íberos, donde ya identifica este suelo pintado como una «alfombra», aunque también ofrece el dibujo invertido sin comprender el diseño, como él mismo reconoce. Años después, A. Arribas (1963, 147, fig. 40) publicó de nuevo el dibujo de Cabré y Motos con el tapiz invertido siguiendo a dichos autores, pero, además, por error, lo interpretó como «decoración de la pared interior de una tumba de Galera», no como una pintura en el suelo, posición que da la clave para su interpretación como alfombra y lo mismo le sucede a H. Schubart (1970, 189, fig. 8), quien también reproduce el dibujo de Cabré y Motos invertido al no entender su significado ${ }^{2}$.

El interés de esta pintura es que constituye la primera documentación conocida de un tapiz de tipo fenicio usado como alfombra, pues se pintó sobre el suelo (Fig. 2). La pieza ofrecía todas las características de un tapiz fenicio, con el fondo rojo, que puede interpretarse como de púrpura, sobre el que destacan seis filas de cuatro flores de loto cada una, por lo que en total suman 24 lotos. Estas flores de loto, aunque

2. Sólo Antonio Blanco, en su artículo «Orientalia» (1956, 4142), ya indicó que los motivos descritos por Cabré, interpretados como altares en serie, debían ser mirados en sentido opuesto para entenderlos adecuadamente como motivos florales: «Si ahora nos fijamos en los motivos de la decoración del pavimento de una tumba de Tútugi (Galera, Granada) y reproducimos invertido el dibujo de Cabré, que el propio autor, ya sin mucho empeño, explicaba como 'especies de aras sobre las que aparecen medias lunas', descubriremos un conjunto sorprendente: un campo de palmetas de cuenco, un poco más esquemáticas que las del marfil de Carmona, y del que se conocen bastantes paralelos orientales, incluso en la decoración de la arquitectura funeraria. Como ejemplo reproducimos aquí un relieve de alabastro, de Aradus, conservado en el Louvre. Por tanto, tomando como positivo lo que Cabré interpretaba como negativo, propondríamos la siguiente descripción para el pavimento de Tútugi: seis franjas de cuatro palmetas blancas y negras sobre fondo rojo, con algunos detalles en amarillo». La misma interpretación la repite el autor en Historia del Arte Hispánico. I.2. La Antigüedad, Madrid, 1981, p. 31. Agradecemos a Manuel Bendala que nos haya recordado esta argumentación de Antonio Blanco. 
bastante esquemáticas, se distingue con claridad, pues así deben entenderse las «aras» y «medias lunas» que interpretaron Cabré y Motos al considerar los lotos invertidos. Las flores de loto aparecen perfectamente alineadas y dispuestas en filas alternas de color blanco y negro, sin excluir que éstas últimas pudieran haber sido originariamente de color azul, pero todas ofrecen una zona en su fondo de color amarillo, que probablemente representa los pistilos, lo que daría al conjunto un evidente colorido, propio de este tipo de tapices orientales.

Al no conservarse los colores no es posible su análisis para conocer su composición, pero cabría suponer, a modo de hipótesis, que el blanco fuera el color natural de la lana, más probable en un tapiz de este tipo que una fibra vegetal; el rojo pudo ser púrpura, sin excluir otras posibilidades (Alfaro, 1984, 200 s.); el amarillo quizás se obtuviera del azafrán o de la ginesta o productos similares (Alfaro, 1984, 201 s.) y el negro pudiera ser lana negra natural (Plin. $N H$ VIII,193) o teñida de algún producto, sin excluir que pudiera haber sido originariamente azul oscuro, que se solía obtener de colorantes como el ferrugo color ${ }^{3}$. Pero tanto el número de 24 lotos como el uso de colores como el rojo, amarillo, blanco y el negro ${ }^{4}$, como su orientación hacia el Este confirman el carácter simbólico de la composición, propio de este tipo de representaciones y adecuada a su uso en una sepultura que, probablemente, hay que suponer regia (vid. infra).

En efecto, el «Tapiz de Galera» debió servir como distintivo regio de la persona enterrada, cuyas cenizas se debieron disponer en una urna que se depositaría sobre el tapiz del mismo modo que se hacía en Oriente al dejar el cuerpo del rey en un lecho cubierto por tapices, como evidencian las tumbas conocidas de Midas o de Ciro (vid. infra). Incluso es tentador pensar que la disposición del muerto sobre un lecho de lotos debía ser una clara referencia a su divinización, pues en joyas, marfiles y bronces los lotos aparecen como símbolo que evidencia que la escena representada sobre ellos ocurre en el Más Allá. En este sentido, estos tejidos por su riqueza eran símbolo de poder, pero sus representaciones añadían un simbolismo religioso y, en relación, con éste, un claro simbolismo social.

Según la escala que ofrece el dibujo publicado de la pieza (Cabré y Motos, 1920, lám. IX), que aparece firmado por un buen dibujante como fue J. Cabré, esta alfombra pintada medía 193,5 cm de largo por 123,5 cm de ancho. Estas medidas podrían equivaler, de forma aproximada, a 4,5 x 7 pies de c. 27,5 cm (que exactamente serían 192,5 x $110 \mathrm{~cm}$ ), una unidad métrica bien

3. Aen. IX, 582; Cat. LXIV, 225-227; Serv. Ad Aen., IX, 579: ferrugo color est purpurae subnigrae, quae fit in Hispania, ut «ferrugine clarus Ibera»; Isid. Orig. XIX, 28; cf. Alfaro, 1984, 200.

4. Para el significado de los colores, puede verse Wunderlich, 1925 y Radke, 1936; el amarillo siempre se ha asociado al oro con significado solar, divino y regio. atestiguada en el mundo ibérico (Almagro-Gorbea, 1988, 125), aunque la imprecisión de las medidas y la proporción de la alfombra, $1: 1,57$, que se desvía de la que parece más lógica de $1: 1,5$, hace que este aspecto metrológico debe ser considerado con precaución. Lo que sí parece evidente es que su anchura debía corresponder a la de un telar normal, mientras que sus medidas hacen suponer que son las de un lecho oriental (Colidis, 1992, 123 s., lám. 21 s.; Rehm, 2005, 125), aunque sean raros los ejemplares conocidos, como los de Salamina (Gubel, 1987, 271) o Gordion (Young, 1981, 187 s.; Simpson, 1990; id. 1996)).

Tampoco es fácil precisar la cronología de la pieza. Según J. Cabré y F. de Motos la pintura actual estaba trazada sobre otra anterior, lo que hace suponer una reapertura de la tumba, quizás para su reutilización dado el uso familiar de estas tumbas de cámara sin excluir otros motivos rituales, pues debe interpretarse como la sepultura de un rex ibérico de Tutugi (vid. infra). Al no haberse conservado su ajuar, su situación permite suponer que corresponde a la fase inicial de la necrópolis de Galera, que se debe remontar a la primera mitad del siglo V a.C., sin excluir una fecha algo anterior, en todo caso no más allá del siglo VI a.C. como máximo, pero, en cualquier caso, parece tratarse de una de las tumbas más antiguas, si no la inicial, de la necrópolis.

La forma, la iconografía y los colores empleados en el «Tapiz de Galera» aseguran que se trata de la reproducción pintada de un auténtico tapiz oriental, a juzgar por el motivo de las flores de loto. Basta para ello compararlo con el tapiz que constituye el fondo de la estela de Arados (Moscati, 1968, lám. 7; id. (ed.), 1988, 300; Falsone, 1988, fig. 34; Markoe, 2000, fig. 59), que ofrece 6 filas de 5 o 6 flores de loto como en el tapiz de Galera, pero menos esquematizadas y dispuestas entre dos cenefas de trenzados, un motivo oriental (Parrot, 1958, 1-3, fig. 1-2) que pasó a ser característico del arte fenicio (Markoe, 1985, 158-159, A-C), lo que confirma que se trata de la representación de un tapiz (Fig. 3). La cronología de la estela de Arados ha sido discutida, pero hoy día se tiende a colocar al inicio de la época aqueménida, hacia el siglo VI o V a.C. (Wagner, 1980, n ${ }^{\circ} 74$ ), que se corresponde perfectamente con el «Tapiz de Galera», aunque éste sea pintado. Otro interesante paralelo para este tipo de tapices es otro relieve, probablemente también de una estela, conservado en el Musée d'Art et d'Histoire de Ginebra, que parece reproducir un tapiz similar, aunque más tosco, en este caso decorado con tres filas superpuestas de 3 o 4 lotos cada una, dispuestos también sobre una escena principal, que ofrece dos grifos rampantes contrapuestos a ambos lados de un Árbol de la Vida (Moscati, 1968, fig. 10), relieve igualmente fechado hacia el siglo VI avanzado o V a.C.

Los relieves de Arados y del Museo de Ginebra confirman que el motivo de las filas de lotos superpuestas debió ser un tema muy común en la tapicería oriental, en concreto fenicia, cuya popularidad confirma su repetición en el tapiz de 


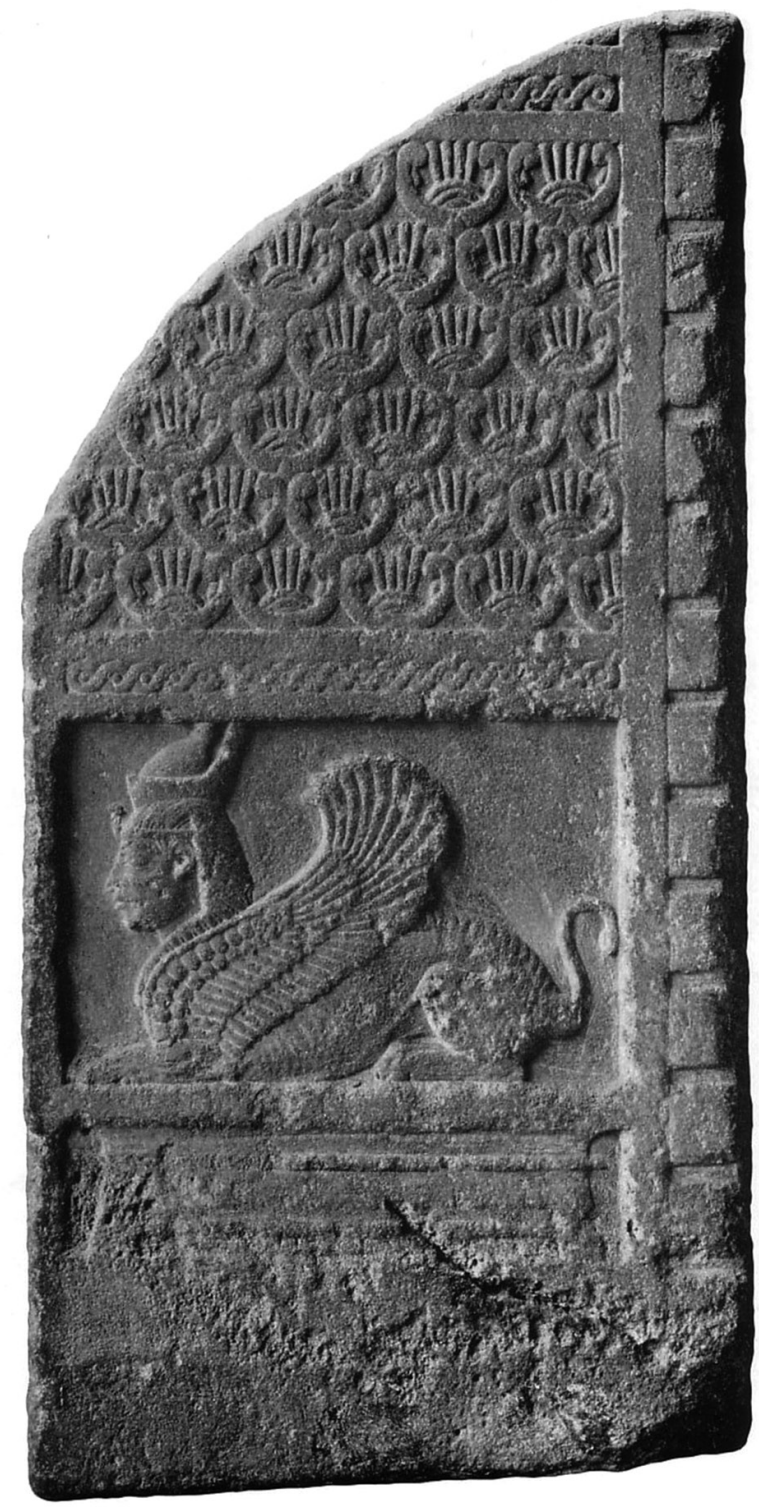

Figura 3: Estela de Arados decorada a modo de tapiz con lotos y esfinge (Según S. Moscati).

Galera, donde se puede conocer con detalle incluso los colores empleados. Pero este motivo de lotos de perfil en el campo que ofrecen los tapices fenicios citados parece derivar de un esquema egipcio, pues ya se documenta en un tejido (Carter y Newberry, 1904, $\mathrm{n}^{\circ} 46562$, lám. I) con el cartucho real de Amenofis II (1428-1401 a.C.) aparecido en la tumba de Tutmosis IV (1401-1390 a.C.), así como en motivos textiles de cuencos de bronce de Nimrud (Falsone, 1988, 100, fig. 32).

En este sentido, el «Tapiz de Galera» ofrece dos aspectos que merecen ser analizados. Uno es su importancia para conocer mejor los tejidos fenicios $y$, en concreto, su relación con la tradición textil «hispano-fenicia» de la Península Ibérica y su importancia para comprender el desarrollo de este artesanado en la cultura Ibérica. Otro, no menos interesante y relacionado con el anterior, es la tradición de tapices del Antiguo Oriente, y en particular su uso en sepulturas regias, como sabemos en los casos de Midas, de Ciro y de las tumbas reales escitas de Pazyryk, en el Altai (vid. infra).

La escasa información existente sobre tejidos fenicios en general se reitera en la Península Ibérica, donde los hallazgos de este tipo resultan sumamente raros (Alfaro, 1983; id., 1984, 136-138), aunque se debe añadir un testimonio excepcional de la tumba de Aliseda (Blanco, 1956, 14; Almagro-Gorbea, 1977, 210, lám. 33,3), pieza que suele pasar desapercibida desde su hallazgo, a pesar de su gran interés por ser el único resto conservado de un bordado de filigrana de oro que con gran probabilidad iría sobre una tela, seguramente de púrpura, lo que da idea del boato de estos tejidos orientales.

Sin embargo, un reciente hallazgo escultórico de la antigua Carmo (Carmona, Sevilla) ofrece un interesante testimonio de ropas bordadas del siglo VI a.C. que ha sido oportunamente valorado (Belén y García, 2005). El bordado consistía en un recuadro con flores de lotos entrecruzadas enmarcado por bandas longitudinales, todo ello siguiendo una composición plenamente oriental, por lo que, a juzgar por el motivo y su cronología, documenta las ricas telas recamadas del artesanado fenicio o hispano-fenicio, por lo que constituye una importante novedad desde este punto de vista (Fig. 4). Además, su estructura en recuadros entre bandas con cenefas ofrece paralelos bastante exactos en las telas representadas en alguna terracota chipriota como los torsos de Salamis-Toumba (Karageorghis y des Gagniers, 1984, 114 s., $\mathrm{n}^{\circ}$ IX,17-18; Karageorghis et alii, 1999, 68-69, $\left.{ }^{\circ} 122-124\right)$ y de Kazaphani 51 y 52 (Karageorghis, 1993, $\mathrm{n}^{\circ}$ 80-82, 33 s., lám. XXI),

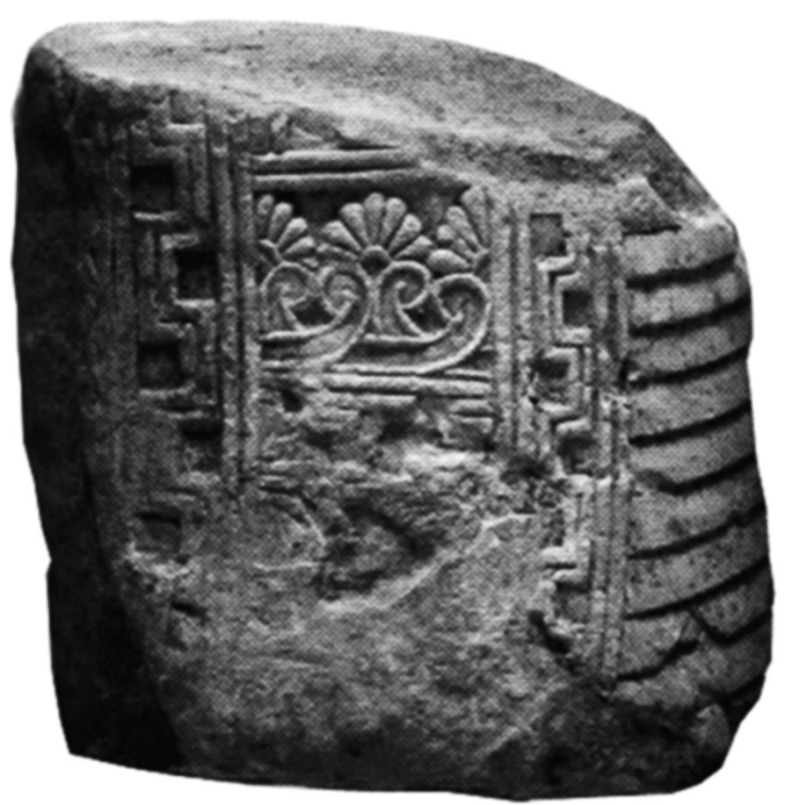

Figura 4: Fragmento de escultura hallada en la antigua Carmo con flores de loto bordadas (según M. Belén). 


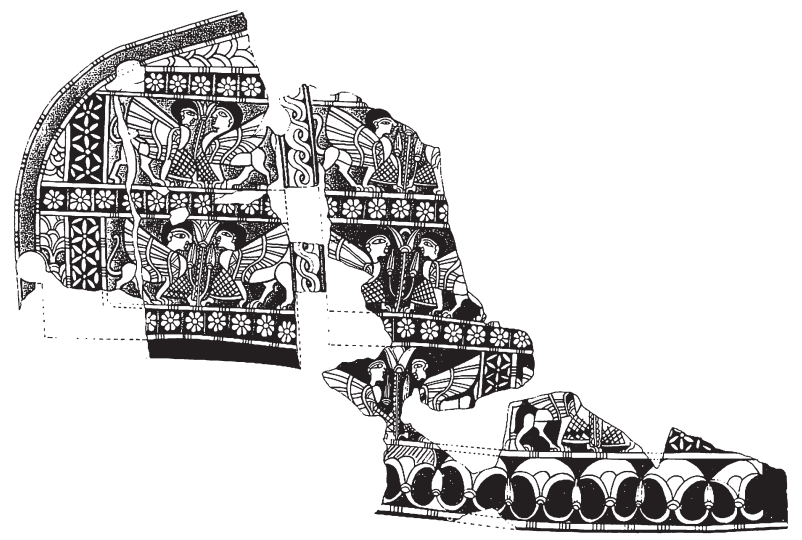

Figura 5: Torso de terracota chipriota de Kazaphani 52 con traje bordado (Según Karageorghis y des Gagniers).

fechados a fines del siglo VII o en la primera mitad del siglo VI a.C. por corresponder al estilo neochipriota. Los torsos están vestidos con telas decoradas con recuadros separados por cenefas características, en los que aparecen temas como esfinges enfrentadas a un Árbol de la Vida en forma de flor de loto (Fig. 5), como las que ofrecería el supuesto tapiz representado en la estela del Museo de Ginebra (vid. supra) y el torso de Kazaphani 207, cuya decoración en relieve ofrece temas que cabe considerar de explícito significado regio (Karageorghis, 1993, 33, fig. 22).

Pero la documentación sobre tejidos hispanofenicios no debe limitarse a los escasos restos arqueológicos. En este sentido debe valorarse

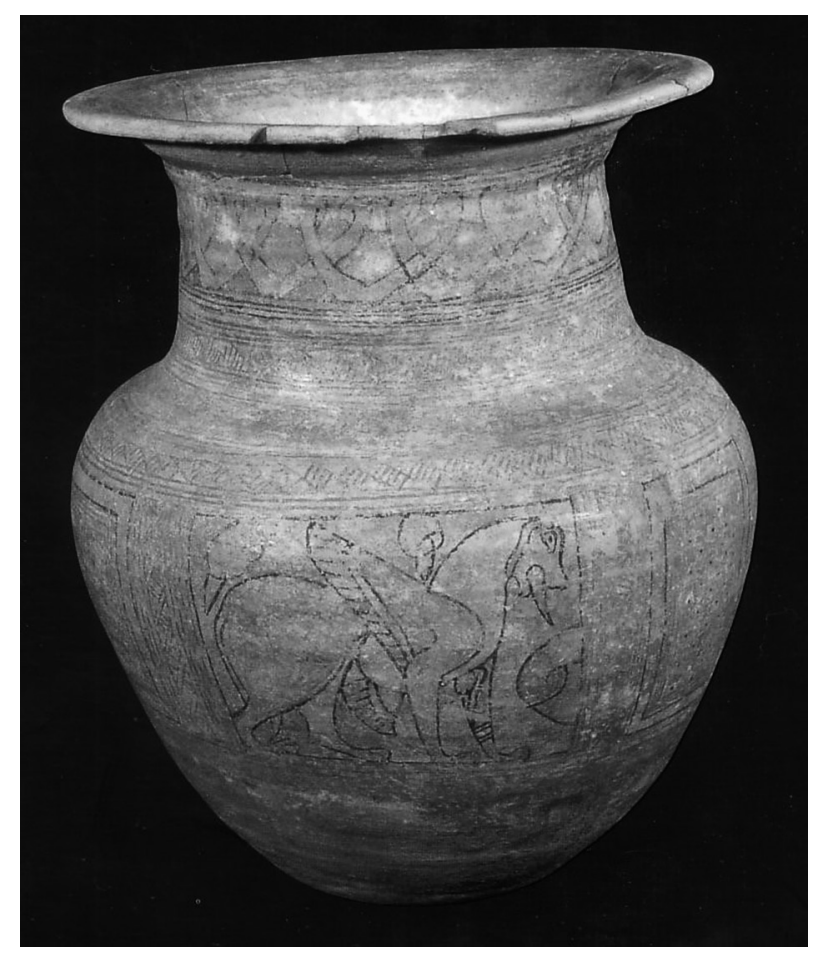

Figura 6: Vaso pintado de Cabra, Córdoba, con motivos inspirados en textiles (Según J. Blánquez).

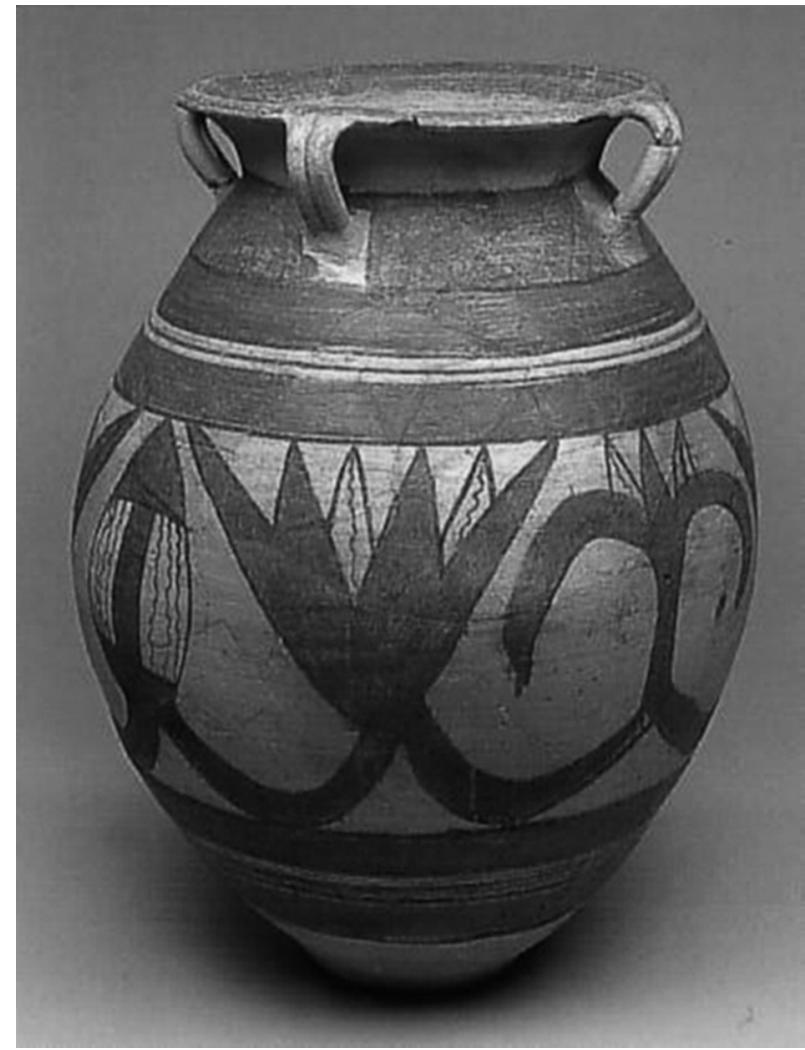

Figura 7: Vaso pintado de Carmo, Sevilla, con motivos inspirados en textiles (Según Mª Belén).

algunas cerámicas polícromas orientalizantes, sin duda inspiradas en los ricos y coloristas tejidos orientales, como se ha señalado ya a propósito de las cerámicas orientalizantes griegas (Brown, 1980). No se puede entrar aquí en un inventario completo, pero basta señalar algunos ejemplos significativos, como los vasos de Cabra (Fig. 6) (Blánquez, 2003), los de Montemolín (Chaves y de la Bandera, 1986), los de la casa del Marqués de Saltillo, en Carmona, decorados con grifos y grandes flores de loto (Fig. 7) (Belén et alii, 1996; Blázquez, 1999; Blánquez, 2003) o las ánforas de Villaricos de fondo blanco (Almagro, 1967). Por el mismo motivo, también parece estar concebida como un posible tapiz la decoración de la bandeja de bronce de Gandul, decorada con seres mitológicos y peces separados por cenefas (Jiménez, 2003, 139 s., lám. 24).

Los motivos y la composición de estas cerámicas resultan característicos y dejan suponer, con gran probabilidad, que se inspiran o copian telas fenicias o fenio-tartésicas. Basta comprobar su composición con el campo ocupado con motivos geométricos, muy característicos y adecuados al tejido en telar, a los que se añaden recuadros con motivos destacados, como animales fantásticos o flores de loto (Blánquez, 2003), como muestra el torso de Kathaphani 52 (vid. supra). En su mayoría predominan colores rojizos-púrpura y amarillentos, como en las cerámicas citadas de Cabra, 
Carmo o Montemolín. Sin embargo, en algún caso, como las citadas ánforas de Villaricos (Almagro, 1967), recuerdan las cerámicas orientalizantes de Fortetsa, en Creta (Brock, 1957), que ofrecen un juego bicolor, en rojo y azul sobre blanco, bien documentado en Oriente, por ejemplo en la referencia de fines del siglo VIII a.C. a los tejidos de Elisa (Ez., 27,7) o en tejidos hallados en el túmulo MM de Gordion (vid. infra), bicromismo que básicamente también pudo haber ofrecido el «Tapiz de Galera», si el color considerado negro hubiera sido originariamente azul oscuro, como cabe suponer (vid. supra) $)^{5}$.

Estas cerámicas de la Península Ibérica dan idea de la importancia de los tejidos hispano-fenicios, que no debió ser menor que la de otros campos altamente especializados del artesanado de lujo en los que eran maestros, como la joyería (Nicolini, 1990), los marfiles (Aubet, 1982; Almagro-Gorbea, 2008) o la toréutica (Jiménez, 2002), tanto más cuando Hispania debía poseer una buena producción de púrpura (Alfaro, 1984, 208 s.).

Esta brillante tradición textil hispano-fenicia resulta esencial para comprender también la importancia del tejido entre los iberos, de la que existen numerosos testimonios y que, como en otras artes, es lógico suponer que se habrían visto influenciados por los fenicios. Basta señalar la importancia de los telares y del tejido como actividad de los palacios orientalizantes tartésicos, de tipo Cancho Roano (Berrocal, 2003; AlmagroGorbea, 1998; Almagro-Gorbea y Domínguez, 1989) o el simbolismo del huso en la perdida estela de La Albufereta de Alicante (Figueras Pacheco, 1956, lám. 21; Llobregat, 1972, lám 7; Cabrera, 1987, fig. 84), con una escena de despedida entre un guerrero y su mujer, que, como atributo, aparece hilando con su uso en la mano siguiendo esquemas del arte griego (Olmos (ed.), 1992, 129) o la placa de terracota con una tejedora procedente de La Serreta de Alcoy, Alicante (Mangas, 1992, 130 y 180), sin olvidar las referencias de Estrabón (III, 144) y Plinio (NH VIII,191) sobre la calidad de lanas y tejidos de los iberos y la del Paradoxógraphus Vaticanus sobre los concursos que los iberos celebraban para premiar a las mujeres que hubieran tejido más y más hermosos vestidos.

El «Tapiz de Galera» también ofrece una valiosa información sobre lo poco que se sabe del artesanado y los tejidos fenicios, a pesar de que fueron famosos por todo el Mediterráneo en la Antigüedad. En efecto, este tapiz completa las grandes lagunas existentes, repetidamente señaladas por casi todos los autores que

5. También las cerámicas chipriotas ofrecen un evidente gusto por este bicromismo a base de rojo y un color oscuro, en este caso, generalmente pardo-negruzco, sobre el fondo blancuzco de la arcilla, característico de la bichrome ware, cuyos productos muchas veces parecen tomados de motivos textiles. Cf. Gjerstad, 1948, fig. 8 s., con motivos orientalizantes en la fase IV; id., fig. 31-35; Karageorghis, 1985, lám. 35-57; etc.). han tratado el tema. Aunque sobre los tejidos existe una amplia documentación en Oriente, en especial en Egipto (Vercoutter, 1964), sobre los fenicios ya Harden $(1962,137)$ señaló cómo we cannot be very precise about the textiles the Phoenicians made, for no fragments of any consequence have survived on any Phoenician site, nor is there anything surely Phoenician even from Egypt, where textiles have been found in quantity. Tampoco Moscati (1972, 499-501; $i d ., 1968,42-81)$ incluye los textiles entre las evidencias fenicias de arte y artesanado o hace referencia a la importancia del artesanado textil fenicio (1969, 83-84) sin dar ejemplos concretos, como tampoco se recoge este aspecto en el catálogo de I fenici (Moscati (ed.), 1988). En fechas más recientes, Markoe (2000, 163), tras dedicar su atención a las famosas telas de los fenicios basándose en los datos habituales tomados de las fuentes antiguas, concluye con escepticismo que, tragically, however, not a sherd of Phoenician fabric has survived to inform us about the appearance or construction of these covered textiles. Estas ideas sobre la falta de conocimientos sobre los tejidos fenicios, quizás excesivamente pesimistas, creemos que pueden ser en parte superadas, al menos, en lo que respecta a la apariencia que tenían, gracias a la información de las piezas comentadas.

Harden (1962) ya hizo un breve aunque interesante análisis del vestido fenicio y consideró que usaban para sus tejidos productos de su tierra y también importados de Egipto, como algodón y lino, además de lana de la alta Mesopotamia. Sobre su aspecto, hace referencia a las representaciones de tipos asiáticos semitas en las pinturas de las tumbas egipcias, en las puertas de Balawat y en los relieves de la huida del rey Luli de Tiro, además de la mención a los policromos vestidos «de los Sidonios» de Homero (VI, 289 s.) y la referencia bíblica al precioso manto de José con muchos colores (Gen., 37,3), semejantes a los que también gustaba llevar a los asirios, tradición que perduró en el Mediterráneo como evidencian las referencias trasmitidas por Plauto (Phoen. 975-6, $1008)^{6}$.

6. Para obtener estos coloridos se recurría a tintes, entre los que se hizo famosa la púrpura (Plinio NH IX,36-40 (125137), obtenida básicamente de dos especies de Murex, el M. trunculus o el M. brandasis (Reinhold, 1970, 9 s.; Alfaro, 1984, 208 s.; Spanier, (ed.), 1987; Zidderman, 1987 y 1990; Karmon y Spanier, 1988; Schneider, 2001; etc.). Sus restos se han encontrado en grandes cantidades en Tiro, Sidón, Sarepta o Dar Essafi, pero, en fechas recientes, se ha señalado su explotación en el mundo fenicio occidental y ambas especies de Murex han aparecido en la factoría precolonial de Huelva, fechada a partir del 900 a.C. (González de Canales et alii, 2004, 176, lám. 72), lo que amplía la zona conocida de obtención de este estratégico producto económico, que se consideraba descubierto por el propio Melqart (Pollux 1, 45; Greg. Naz., Oratio 4, 108; Cassiod. Var. 1,2) y del que los fenicios parece haber tenido en la práctica un monopolio de hecho. 
Junto a algunos bajorelieves que representan tapices, como el de Nínive (Pottier, 1924, $\mathrm{n}^{\circ}$ 74; Orthmann, 1975, 323, lám. 23; Albenda, 1984), resulta muy interesante, aunque poco tenida en cuenta por los arqueólogos, la valiosa información que ofrecen algunos textos orientales, muchos de ellos de contenido económico. Los documentos epigráficos ilustran muchos aspectos relacionados con el tejido que no es oportuno tratar aquí, pero que confirman que la existencia de tapices estaba ampliamente documentada en Oriente. El término mardatu/mrdt, aunque de etimología incierta (Ribiquini y Xella, 1985, 50), designaba tejidos de amplias dimensiones que se han considerado de origen sirio (Barrelet, 1977, 57), en los que se incluirían los tapices, pero que también pudiera designar alfombras y elementos similares (Oppenheimer, 1952, 136-137; Speiser, 1954, 25; Köcher, 1958, 306; Mayer, 1977; Durand, 1983, 409 s.; Tomabechi, 1983; Ribiquini y Xella, 1985, 50-51), en alguna ocasión podían ser de lino (RS 15.135:5) o con orlas o franjas (KTU 4.205:4.6), aunque sea lógico pensar que serían de lana si se destinaban a cubrir el suelo a modo de alfombras. Referencia a estos tapices se conocen en Capadocia, Nuzi, Alalakh, Mari, Ugarit, Asiria y en Ebla, donde, con la forma ma-ra-tum, un documento económico valora una de estas piezas en tres siclos dilmuniti de oro (MEE 2, n. 16 r. II2, 113-114), lo que evidencia que eran tejidos de gran precio, pues era uno de los regalos al rey de Amurru (KTU 2.72: 25).

También en Mari se conocen tejidos denominados mardatu, término que igualmente emplean los textos asirios para describir tejidos de colores usados en el palacio real hasta el I milenio a.C. Como ejemplo, cabe citar un texto asirio del siglo XIII a.C. que hace referencia al tejido de un tapiz-mardatu decorado con coloridas figuras de dioses (Köcher, 1958; Barrelet, 1977; Tomabechi, 1983, 127), probablemente como las pinturas que decoraban las paredes de las salas principales de los palacios orientales (Parrot, 1958; Moortgat, 1959), que en ocasiones parecen copiar tapices (Strommenger, 1962, 32; Moortgat, 1959, 12). Algunos de estos tapices eran usados como alfombras $\mathrm{y}$, en ocasiones, se han representado en piedra (Pottier, 1924, no 74; Orthmann, 1975, 323, lám. 23; Albenda, 1984), por lo que Asiria debió haber jugado un importante papel en la creación y transmisión del tapiz para el suelo o alfombra (Dalley, 1991).

Esta tradición de tapices se extendió desde Mesopotamia a Fenicia, donde debió alcanzar un particular desarrollo, pues Ezequiel $(27,24)$ hace referencia a tapices tejidos en varios colores, de fuertes y retorcidos hilos... (Lepiski, 1985). Pero también sabemos que se extendió a otros lugares, pues un tapiz hecho con la técnica del kilim actual apareció en la más rica tumba de Gordion, fechada en el siglo VIII a.C., que se ha atribuido al rey frigio Midas. En esta tumba las paredes y el lecho del rey muerto estaban cubiertas de tapices (Young, 1981). Esta tradición de cubrir paredes y suelos de las tumbas reales con tapices, probablemente a imitación de sus palacios, llegó hasta las tumbas de los reyes hallstátticos, como la de Hochdorf (Biel, 1985, fig. 33, 65, lám. 10-11, etc.) y también se han hallado tapices en las tumbas heladas escitas de Pazyrick, en el Altai, fechados en los siglos V-IV a.C.

Estos ejemplos confirman que el uso de tapices y alfombras en sepulturas regias parece ser un hecho bastante habitual, según se deduce de los hallazgos citados, a los que cabe añadir otros, como una interesante referencia conservada sobre la tumba de Ciro, contexto que ayuda a comprender el valor y significado del «Tapiz de Galera», cuyo uso se adecua al de los tapices en Oriente como una pieza singular de tejido empleada en palacios y sepulturas regias. Un caso bien ilustrativo es el túmulo real MM de Gordion (Young, 1981), atribuido al rey frigio Midas y que se ha fechado a fines del siglo VIII a.C., se acepte la fecha histórica de la muerte de Midas el 718 a.C. o la propuesta por los análisis de dendrocronología del 740 a.C. (Kohler y Ralph, 1961, 361-363). Midas yacía en su cámara mortuoria sobre tejidos apilados teñidos de púrpura y de azul, que se han conservado relativamente bien en su cámara junto a sus muebles de madera, existiendo también telas dispuestas en las paredes de la cámara (Bellinger, 1962; Young, 1981, 7-9, 100 s., 189-190; Ellis, 1981). En este conjunto de tejidos, destaca el utilizado como cobertor o colcha del lecho situado en la esquina NW de la tumba, que confirma el uso de costosos tapices para la sepultura de los soberanos. También resulta muy ilustrativa la descripción de la tumba de Ciro transmitida por el Anábasis de Alejandro Magno de Arriano (VI,29,5-6), obra escrita en el siglo II de JC., pero basada en Aristóbulo, escritor de la época de Alejandro, quien describe como «...hay un sarcófago de oro, en el que había sido enterrado el cuerpo de Ciro; un lecho estaba a su lado con patas de oro labradas; sus colchas eran tapices babilónicos y la alfombra, tapices de púrpura...» $\rangle^{7}$.

Otro ejemplo comparable puede ser el espléndido conjunto de tapices de los kurganes de Pazyryk, en el Altai (Jettmar, 1964, 106 s., fig. 87 y 103; Rubinson, 1990; Böhmer y Thompson, 1991; Stronach, 1993), fechados en el siglo V a.C. (Hajdas et alii, 2004). Destaca la hermosa pieza del túmulo $\mathrm{V}$, fechado hacia el 400 a.C., de forma casi cuadrada de $2 \times 2$ m, hecho de nudos y formado por un centro con 24 florones en recuadros que queda rodeado por cenefas con animales, flores y jinetes. Aunque la pieza es escita por su técnica y estilo y, justamente se ha considerado como uno de los precedentes del artesanado del tejido propio de

7. ...la base de la tumba era cuadrada construida con sillares escuadrados. Encima había una cámara también cuadrada con techo de piedra con una puerta de acceso tan pequeña que era dificil a un hombre de baja estatura atravesarla. En la cámara había un sarcófago de oro con el cuerpo de Ciro en su interior y junto al sarcófago habia un lecho con patas de oro labradas; sus colchas eran tapices babilónicos y la alfombra, tapices de púrpura...». 
los pueblos seminómadas de las estepas, no cabe duda de que refleja la tradición oriental documentada igualmente en las tumbas de Ciro y de Midas. Y la misma costumbre se habría difundido por Hispania en el Periodo Orientalizante, pues a este «Tapiz de Galera» se añaden el lecho de Torrejón de Abajo, Cáceres (Jiménez Ávila, 2002, 246 s.) y el uso habitual de diphroi en Medellín (Jiménez Ávila, 2007, e.p.), que indican una tradición de dormir en lechos que implicaba el uso de este tipo de tapices o coberteras.

En conclusión el «Tapiz de Galera» puede considerarse uno de los más interesantes testimonios llegados hasta nosotros del floreciente artesanado del tejido en el mundo fenicio. Junto a los paralelos aquí recogidos, entre los que no conviene olvidar la rica información proporcionada por las cerámicas polícromas, aunque no documenta los aspectos técnicos, sí ilustra el aspecto espectacular y el boato que debían ofrecer estos tejidos orientales. Además, como en otros campos del artesanado fenicio, estas creaciones parecen en gran medida destinadas a las elites sociales, pues, en concreto, estos valiosos tapices se documentan como posesión de reyes, tradición ya evidenciada por el citado texto de Amurru (KTU 2.72: 25) y confirmada por las tumbas de Gordion (Simpson, 1990) y de Ciro (Arr. $A n a b .$, VI, 29). Este aspecto permite plantear si el «Tapiz de Galera» no debió tener un uso similar, salvando las lógicas distancias, como propiedad y, quizás, como distintivo regio y de heroización de la persona enterrada, un rey de la antigua Tutugi, cuyas cenizas se debieron disponer en una urna que quedaría depositada sobre el tapiz del mismo modo que se hacía en Oriente al dejar el cuerpo del rey en un lecho cubierto por tapices. Una vez más, a la riqueza que suponen estos tejidos en sí mismos se añadía su simbolismo religioso y, en relación, con éste, su simbolismo social, funciones que se corresponden perfectamente con la cultura fenicia y los consiguientes procesos de aculturación, pues este «Tapiz de Galera» sería una nueva confirmación de la existencia de elites regias de origen orientalizante en la Hispania prerromana (AlmagroGorbea, 1996, 44-76).

\section{Dr. Martín Almagro-Gorbea Real Academia de la Historia C/ León, 21 28014 Madrid anticuario@rah.es}

\section{BIBLIOGRAFÍA}

AlbendA, P., 1984: «Assyrian Carpets in Stone», The Journal of the Ancient Near East Society, 10, 1-34.

AleKseev, A.Yu. et alii, 2001: «A Chronology of the Scytians Antiquities of Eurasia based on New Archaeological and 14C Data», en I. Carmi y E. Boaretto (eds.), Proceedings of the 17th International 14C Conference, Radiocarbon, 43,2B, 1085-1107.
Alfaro Giner, C., 1983: «Fragmentos textiles del sarcófago antropomorfo femenino de Cádiz», Homenaje al Prof. Martín Almagro Basch, II, 281-289, Madrid.

Alfaro Giner, C., 1984: Tejido y cestería en la Península Ibérica, Bibliotheca Praehistorica Hispana 21, Madrid.

AlMAgro BASCH, M., 1967: «Dos ánforas pintadas de Villaricos», Ommage a Fernand Benoit en Rivista di Studi Liguri, 33, 345-353.

Almagro-GorbeA, M., 1988: «El pilar-estela de Coy», Homenaje a Samuel de los Santos, 125-131, Albacete.

Almagro-GorbeA, M., 1996: Ideología y Poder en Tartessos y el mundo ibérico, Madrid.

Almagro-GorbeA, M., 1998: «¿Harenes en Tartessos? En torno a la interpretación de Cancho Roano», De Oriente a Occidente en Homenaje al Dr. Emilio Olábarri, Bibliotheca Salmanticensis 205, 113-137, Salamanca.

Almagro-GorbeA, M., 2008: «Objetos de marfil y hueso», en M. Almagro Gorbea (dir.), La necrópolis de Medellín. II, Estudio de los hallazgos, Biblioteca Archaeologica Hispana 26, vol 2, 401-512, Madrid.

Almagro-GorbeA, M., y DomíngueZ, A., 1989: «Cancho Roano. El palacio de Cancho Roano y sus paralelos arquitectónicos y funcionales», Zephyrus, 41-42, 339-382.

ARriBAS, A., 1963: The Iberians, London.

AUBET, M ${ }^{\text {a }}$.E., 1982: «Die westphönizischen Elfenbeine aus dem Gebit des unteres Guadalquivirs», Hamburger Beiträge zur Archäologie, 9, 15-72.

BARRELET, Th., 1977: «Un inventaire de Kar Tukulti Ninurta: textiles décorés assyriens et autres», Revue d'Assyriologie et d'Archéologie orientale, 71:1, 51-92.

BELÉn, Ma et alii, 1996: Excavaciones en Carmona. La casa-palacio del Marqués de Saltillo, Sevilla.

Belén, Ma y GARcíA Morillo, Ma C., 2005: «Carmona. Una ciudad tartésica con estatuas», en S. Celestino y J. Jiménez Ávila (eds.), El Periodo Orientalizante, II, Anejos de Archivo Español de Arqueología XXXV, 1199-1213, Madrid.

BELLINGER, L., 1962: «Textiles from Gordion», Bulletin of the Needle and Bobbin Club, 46, 4-33.

BERROCAL, L., 2003: «El instrumental textil de Cancho Roano: consideraciones sobre sus fusayolas, pesas y telares», en S. Celestino (ed.), Cancho Roano IX. Los Materiales Arqueológicos II, 213-297, Badajoz.

BIEL, J., 1985: Der Keltenfürst von Hochdorf, Stuttgart.

Blanco FreiJeIro, A., 1956: «Orientalia», Archivo Español de Arqueología, 29, 3-51.

BlÁNQueZ, J. J. (ed.), 2003: Cerámicas Orientalizantes del Museo de Cabra, Cabra.

BLÁZQUEZ, J. Má., 1998-1999: «Temas religiosos en la pintura vascular tartésica e ibera y sus prototipos del Próximo Oriente», Lucentum, XVII-XVIII, 93-116.

BöHMer, H. y Thompson, J., 1991: «The Pazyryk Carpet: A Technical Discussion», Notes in the History of Art, 10:4, 30-36.

Brock, J.K., 1957: Fortetsa. Early Greek Tombs Near Knossos, Annual of the British School in Athens 52, Athens.

Brown, K. S., 1980: The Question of Near Eastern Textile Decoration of the Early First Millenium B.C. as 
a Source for Greek Vase Painting of the Orientalizing Style, Philadelphia.

CABRÉ, J., y Motos, F. de, 1920: La necrópolis ibérica de Tútugi (Galera, Provincia de Granada), Junta Superior de Excavaciones y Antigüedades 25, Madrid.

CABRERA, P. y GRIÑó, B., 1987: «¿Una diosa tejedora en el allende?», Estudios de Iconografia II, Coloquios sobre el Puteal de la Moncloa), 193-203, Madrid.

CARTER, H. y NEWBERRY, P.F., 1904: Catalogue général des Antiquités Egyptiennes du musée du Caire. The Tomb of Thoutmôsis IV, Westminister.

CHAVEs, F. y BANDERA, M ${ }^{\mathrm{a}}$ L. de la, 1986: «Figürlich verzierte Keramik aus dem Guadalquivir-Gebiet. Die Funde von Montemolín (bei Marchena, prov. Sevilla)», Madrider Mitteilungen, 27, 117-150.

ColidIS, N., 1992: Möbel in Ton. Untersuchungen zur archäologischen und religionsgeschichten Bedeutung der Terrakottamodelle von Tischen, Stülen und Betten aus dem Altem Orient, Münster.

DALleY, S., 1991: «Ancient Assyrian Textiles and the Origins of Carpet Design», Iran, 29, 117-135.

DURAND, J.-M., 1983: Textes administratifs des salles 134 et 160 du palais de Mari, Archives Royales de Mari, Transcription et Traduction (ARMT) XXI, Paris.

ELLIS, R., 1981: «The Textile Remains», en R. S., Young, 1981, The Gordion Excavations Final Reports 1. Three Great Tumuli, University Museum Monograph 43, 294 310, Philadelphia.

FALSONE, G., 1988: «La Fenicia come centro di lavorazione del bronzo nell'Età del Ferro», Dialoghi di Archeologia, 6: $1,79-110$.

FigUeRAS PACHECO, F., 1956: La necrópolis ibero-púnica de la Albufereta de Alicante, Alicante.

GARCÍA BELLIDO, A., 1954: «Arte ibérico», en R. Menéndez Pidal (dir.), Historia de España, vol. I,3, 371-675, Madrid.

GJERSTAD, E., 1948: The Swedish Cyprus Expeditiom IV,2. The Cypro-geometric, Cypro-archaic and Cypro-classical Periods, Stockholm.

GonzÁlez de CANales, F., Serrano, L. y Llompart, J., 2004: El emporio fenicio precolonial de Huelva (ca. 900-770 a.C.), Madrid.

GONZÁLEZ Hontoria, G. y Timón, M.P., 1993: Telares manuales en España, Madrid

Gubel, E., 1987: Phoenician Forniture, Studia Phoenicia VII, Louvain.

GUBEL, E., 1992: s.v. Textile, Dictionnaire de la civilisation Phénicienne et Punique, 446, Leiden.

HAJDAS, I., BONANI, G. y SEIFERT, M., 2004: «Radiocarbon and calendar chronology of Ulandryk 4 and Pazyryk 2 tombs», Oxford University School of Archaeology Monograph, 62, 201-208.

JetTManN, K.L., 1964: Die frühen Steppenvölker. Der eurasitische Tierstil Enstehung und socialer Hintergrund, Baden-Baden.

JimÉNEZ ÁVILA, J., 2002: La toreútica orientalizante en la Península ibérica, Bibliotheca Archaeologica Hispana 16, Madrid.
JiMÉNEZ ÁvILA, J., 2007, e.p.: «Los diphroi», en M. Almagro-Gorbea (dir.), La Necrópolis de Medellín, II, Bibliotheca Archaelogica Hispana 26, Madrid.

KarageOrghis, V., 1985: Cypriote Antiquities in the Pierides collection. Larnaca. Chyprus, Larnaca.

Karageorghis, V., 1993: The Coroplastic Art of Ancient Cyprus, III. The Cypro-Archaic Period. Large and Medium Size Sculpture, Nicosia.

KARAgeOrghis, V. y DES GAGNIERS, J., 1974: La céramique chypriote de style figuré, Âge du Fer (1050-500 avant J.C.), Roma.

KARAgeORGHIS, V., VASSILIKA, E. y Wilson, P., 1999: The Art of Ancient Cyprus in the Fitzwilliam Museum, Cambridge.

Karmon, N. y Spanier, E., 1988: «Remains of Purple Dye Industry Found at Tell Shiqmona», Israel Exploration Journal, 38, 184-186.

KÖCHER, F., 1957-1958: «Ein Inventartext aus Kar-TukultiNinurta», $A f O, 18,306$.

KoHLER, E.L. y RALPH, E. K., 1961: «C-14 Dates for Sites in the Mediterranean Area», American Journal of Archaeology, 65:4, 357-367

LEPISKI, E., 1985: «Products and Brokers of Tyre according to Ezekiel 27», Studia Phoenicia, 3, 213-220.

LILliU, G. y SCHUBART, H., 1970: Civilisations anciennes du Bassin méditerranéen. Corse - Sardaigne - Baléares - Les Ibères, L'Art dans le monde, Paris.

LlobregAt, E., 1972: Contestania Ibérica, Alicante.

MANGAS, J., 1992: «Las referencias a la imagen ibérica en los autores antiguos», en Olmos, R. (ed.), 1992, La sociedad ibérica a través de la imagen, 184-189, Madrid.

Markoe, G., 2000: Phoenicians, Avon.

MAYER, W.R., 1977: "Mardatu "Teppisch"», Ugarit Forschungen, 9, 173-189.

Moortgat, A., 1959: Altvorderasiatische Malerei, Berlin.

MoscATI, S., 1968: The World of the Phoenicians (Il mondo dei fenici), London.

Moscati, S., 1972: I Fenici e Cartagine, Torino.

Moscati, S. (ed.), 1988: I Fenici, Milano.

NicolinI, G., 1990: Techniques des ors antiques. La bijouterie ibérique du VII au VI siècle, Paris.

Olmos, R. (ed.), 1992: La sociedad ibérica a través de la imagen, Madrid.

OpenHEIMER, A. L., 1952: «The Archives of the Palace of Mari. A Review Article», Journal of Near Eastern Studies, 11: 2, 129-139.

OrThmanN, W., 1975: Der Alte Orient (Propyläen Kunstgeschichte), Berlin.

PARrot, A., 1958: Misión archélogique de Mari, II. Le Palais, 2. Peintures mureles, Paris.

Pereira, J., Chapa, T., MAdrigal, A., Uriarte, A. y MayoRAL, V., (eds.), 2004: La Necrópolis de Galera (Granada). La colección del Museo Arqueológico Nacional, Madrid.

PotTIER, E., 1924: Catalogue des antiquités assyriennes, Paris.

RADKE, G., 1936: Die Bedeutung der weissen und schwarzen Farbe in Kult und Brauch der Griechen und Römer (Diss.), Berlin. 
REHM, E., 2005: «Assyrische Möbel für den assyrischen Herrschen», en C.E. Suter y Chr. Uelinger (eds.), Crafts and Images in Contact, Studies on Eastern Mediterranean art of the first milenium BCE, Göttingen.

ReInHOld, M., 1970: The History of Purple as a Status Symbol in Antiquity, Collection Latomus 116, Brussels.

RIBIQUINI, S. y XELLA, P., 1985: Terminología del tessili nei testi di Ugarit, Colezione di studi fenici 20, Roma.

RubINSON, K.S., 1990: «The Textiles from Pazyryk: A Study in the Transfer and Transformation of Artistic Motifs», Expedition, 32:1, 49-61.

SCHNEIDER, H. (2001): «Purpur» en Neue Pauly, Volume 10, 604-605. Stuttgart/Weimar.

SchuBART, H., 1970: «Les Ibères», en G. Lilliu y H. Schubart, Civilisations anciennes du Bassin méditerranéen. Corse - Sardaigne - Baléares - Les Ibères, L’Art dans le monde, Géneve.

SimpSON, E., 1990: "“Midas 'Bed”" and a Royal Phrygian Funeral», Journal of Field Archaeology, 17:1, 69-87.

SiMPSON, E., 1996: «Phrygian Furniture from Gordion», en G. Herrmann (ed.), The Furniture of the Western Asia. Ancient and Traditional, 187-209, Mainz.

SPANIER, E. (ed.), 1987: The Royal Purple and the Biblical Blue: The Study of Chief Rabbi Isaac Herzog and Recent Scientific Contributions, Jerusalem.
SPEISER, E. A., 1954: «The Alalakh Tablets», Journal of the American Oriental Society, 74: 1, 18-25.

Strommerger, E., 1962: Fünf Jahrtausende Mesopotamien: die Kunst von Anfängen um 5000 v. Chr. bis zu Alexander der Grossen, München.

StronACH, D., 1993: «Patterns of Prestige in the Pazyryk Carpet: Notes on the Representational Role of Textiles in the First Millennium B.C.», en M. L. Eiland, Jr., R. Pinner y W. B. Denny (eds.), Oriental Carpet and Textile Studies, IV, 19-34, Berkeley.

TomaBeCHI, Y., 1983: «Wall Paintings from Dur Kurigalzu», Journal of Near Eastern Studies, 42: 2, 123-131.

VerCoutTer, J., 1964: «s.v. Tissage, Egypte», Dictionnaire archéologique des techniques, II, 978-980, Paris.

WAGNER, P., 1980: Der ägyptische Einfluss aud die phönizische Architectur, Bonn.

WundERLICH, E., 1925: Die Bedeutung der Roten Farbe im Kultus der Griechen und Römer, Huyesen.

Young, R. S., 1981: The Gordion Excavations Final Reports 1. Three Great Tumuli, University Museum Monograph 43, Philadelphia.

ZIDDERMAN, I., 1987: «First Identification of Authentic tekelet», Bulletin of the American School of Oriental Research, 265, 25-33. 